\title{
IMPACTO DO ENCHIMENTO DO RESERVATÓRIO DE UMA UHE SOBRE A DINÂMICA DE UM FRAGMENTO DE FLORESTA OMBRÓFILA MISTA EM SANTA CATARINA
}

\section{IMPACT OF WATER RESEVOIR FILLING OF AN HYDROELETRIC PLANT ON DYNAMICS OF AN ARAUCARIA FOREST FRAGMENT IN SANTA CATARINA}

Carla Luciane Lima ${ }^{1}$ Ana Carolina da Silva ${ }^{2}$ Pedro Higuchi ${ }^{2}$ Aline Pereira Cruz ${ }^{3}$ Ricardo de Vargas Kilca $^{4}$ Amanda da Silva Nunes ${ }^{1}$ Mariele Alves Ferrer da Silva ${ }^{1}$ Juliana Pizutti Dallabrida ${ }^{1}$ Vanessa Fátima Soboleski ${ }^{1}$ Aline Gross ${ }^{1}$

\section{RESUMO}

O presente estudo teve como objetivo investigar o impacto do enchimento do reservatório de uma usina hidrelétrica sobre as taxas de dinâmica do componente arbóreo em uma floresta adjacente. Para isso, foram alocadas 48 parcelas em três setores do fragmento: adjacente às margens do reservatório, meio da encosta e topo da encosta. Um ano após o enchimento do reservatório, todos os indivíduos arbóreos com circunferência a altura do peito (CAP) $\geq 15,7 \mathrm{~cm}$ foram avaliados (identificados e mensurados), e dois anos após o enchimento foi realizado o estudo de dinâmica, com as árvores sobreviventes remedidas, as mortas quantificadas e as recrutas incorporadas. Foi realizado o levantamento das variáveis ambientais edáficas, topográficas, de abertura do dossel e de impacto ambiental. Foram calculadas as taxas de dinâmica. Para ordenação das variáveis ambientais foi aplicada uma Análise de Componentes Principais (PCA) e a influência de gradientes ambientais sobre as taxas demográficas da comunidade foi verificada por meio de regressão logística. A dinâmica apresentou estabilidade no número de indivíduos, porém, com maior ganho $\left(3,64 \%\right.$.ano $\left.{ }^{-1}\right)$ que perda $\left(1,62 \% . a^{-1}\right)$ em área basal. Entre os setores houve distinções, sendo o setor 1 caracterizado pela maior taxa de perda em área basal $\left(2,51 \%\right.$.ano $\left.{ }^{-1}\right)$. Houve pouca relação das taxas demográficas com as variáveis ambientais analisadas, indicando que a maior influência encontrada sobre o crescimento das árvores está associada a variáveis não mensuradas. O presente estudo indica que, dois anos após o enchimento do reservatório, foi possível perceber os primeiros efeitos da influência do lago da hidrelétrica na comunidade arbórea.

Palavras-chave: dinâmica florestal; comunidade de espécies arbóreas; impacto ambiental.

\begin{abstract}
We aimed to investigate the impact of the water reservoir of a hydroelectric power station on the tree component dynamics in an adjacent forest. For this, we allocated 48 plots in three sectors: bottom, adjacent to water reservoir, middle slope and upper slope. One year after the water filling, we measured (circumference at breast height - cbh and identified all trees with $\mathrm{cbh}) \geq 15,7 \mathrm{~cm}$, followed by the dynamics study in the next year, with the re-measurement of survival trees and quantification of mortality and recruitment. We evaluated environmental variables (edaphics, topographics and environmental impacts). We determined

1 Engenheira Florestal, MSc., Departamento de Engenharia Florestal, Universidade do Estado de Santa Catarina, Av. Luiz de Camões, 2090, CEP 88520-000, Lages (SC), Brasil. carla_engflorestal@yahoo.com.br / amandaeng.f@ gmail.com/mariele.ferrer@hotmail.com/juli_ajuri@hotmail.com/vanessasoboleski@hotmail.com/alinegros@ hotmail.com

2 Engenheiro Florestal, Dr., Professor do Departamento de Engenharia Florestal, Universidade do Estado de Santa Catarina, Av. Luiz de Camões, 2090, CEP 88520-000, Lages (SC), Brasil. carol_sil4@yahoo.com.br / higuchip@ gmail.com

3 Bióloga, MSc., Departamento de Engenharia Florestal, Universidade do Estado de Santa Catarina, Av. Luiz de Camões, 2090, CEP 88520-000, Lages (SC), Brasil. a.line_cruz@yahoo.com.br

4 Biólogo, Dr., Pós-Doutorando do Programa de Pós-Graduação em Engenharia Florestal, Universidade do Estado de Santa Catarina, Av. Luiz de Camões, 2090, CEP 88520-000, Lages (SC), Brasil. ricardokilca@yahoo.com.br
\end{abstract}

Recebido para publicação em 11/09/2016 e aceito em 21/07/2017

Ci. Fl., v. 28, n. 3, jul. - set., 2018 
the dynamics rates and applied a Principal Component Analysis (PCA) to the ordination of environmental variables and analyzed the influence of environmental gradients on community demographics rates through logistic regression. The dynamics presented number of individuals stability, but a greater basal area gain (3.64\%.year $\left.{ }^{-1}\right)$ than loss $\left(1.62 \%\right.$.year $\left.^{-1}\right)$. There were differences among sectors, with a greater loss in bottom sector $\left(2.51 \%\right.$.year $\left.{ }^{-1}\right)$ than others. There was a weak relation between analyzed environmental variables, suggesting that trees growth is mostly related to non-measured variables. The present study indicates that, two years after the water filling, it is possible to detect the short-term impacts of the reservoir of hydroelectric power station on tree community.

Keywords: forest dynamics; tree species community; environmental impact.

\section{INTRODUÇÃO}

O Estado de Santa Catarina está totalmente inserido no Bioma Mata Atlântica e é composto por diversas fitofisionomias, sendo que na porção centro-oeste há predominância da Floresta Ombrófila Mista (FOM), que entra em contato com a Floresta Estacional Decidual (FED) (IBGE, 2012), acompanhando os vales dos rios que compõem a Bacia Hidrográfica do Rio Uruguai. Essa bacia compreende um amplo território, no qual está inserida a sub-bacia hidrográfica do Rio Canoas.

Nos últimos anos, devido à demanda energética do país, os rios da região têm recebido empreendimentos hidrelétricos, cujos reservatórios de água comumente ocasionam uma redução e exposição de fragmentos florestais remanescentes a uma nova condição ambiental, caracterizada pela proximidade dos reservatórios de água. Assim, o estresse ocasionado por essa exposição recente a uma condição de maior encharcamento do solo pode afetar a composição florístico-estrutural da vegetação arbórea ao longo do tempo.

Os efeitos graduais temporais dos reservatórios na vegetação são pouco estudados (e.g. GUSSON et al., 2012), apesar de serem bastante importantes. Dentre os poucos estudos que abordam os impactos ao longo do tempo do enchimento de reservatórios, destacam-se os de Nilsson e Berggren (2000), que estudaram as mudanças ecológicas em um contexto global, e Vale et al. (2013) e Lopes et al. (2015) em Florestas Decíduas e Semidecíduas no sudeste do Brasil.

Considerando que diferentes fitofisionomias podem responder de forma distinta aos efeitos dos enchimentos de reservatórios, para maior compreensão desses impactos e entendimento de como esses afetam a vegetação de áreas em ecótonos de FOM e FED, são necessárias investigações nessas regiões. Dessa forma, o presente trabalho buscou identificar se as taxas de dinâmica do componente arbóreo podem estar refletindo o impacto do enchimento do reservatório da Usina Hidrelétrica (UHE) Garibaldi, em uma floresta adjacente às margens do lago, dois anos após o enchimento, e se estas se relacionam às variáveis ambientais da área. Nessa floresta foram definidos três setores, sendo o primeiro às margens do lago e os demais seguindo a encosta. Neste trabalho foi investigado se as taxas de dinâmica no setor adjacente às margens do lago apresentam padrões diferenciados quando comparadas com os demais setores, pois este se encontra com maior influência hídrica. Além disso, foi avaliado se as variáveis ambientais mensuradas no setor adjacente ao lago apresentam influência significativa nas taxas de dinâmica e difiram quando comparadas com os demais setores, o que poderia representar uma resposta ao distúrbio causado pelo enchimento do reservatório.

\section{MATERIAL E MÉTODOS}

A área de estudo localiza-se em um fragmento florestal situado nas margens do reservatório da UHE Garibaldi, em um trecho localizado no município de São José do Cerrito-SC (Figura 1). Está localizado a uma latitude de $27^{\circ} 55^{\prime} 73^{\prime}$ 'S e longitude de $50^{\circ} 95^{\prime} 60^{\prime}$ 'O, situado a aproximadamente $17 \mathrm{~km}$ à montante do local de barramento do rio a uma altitude de 700 a $800 \mathrm{~m}$. De acordo com a classificação climática de Köppen, o clima da região é do tipo mesotérmico úmido com verão ameno $(\mathrm{Cfb})$, com temperatura média anual variando de 15,8 a $17,9^{\circ} \mathrm{C}$ e com precipitação pluviométrica total anual de 1.460 a $1.820 \mathrm{~mm}$ (EMPRESA DE PESQUISA AGROPECUÁRIA E EXTENSÃO RURAL DE SANTA CATARINA, 1999). Os solos predominantes na região são Nitossolos Háplicos e Cambissolos Húmicos, desenvolvidos a partir 
de rochas basálticas (EMBRAPA, 2004). A topografia varia de ondulada a acidentada. A formação florestal encontrada é a Floresta Ombrófila Mista em transição com a Floresta Estacional Decidual (IBGE, 2012), sendo que a área de estudo apresenta estágio sucessional avançado.

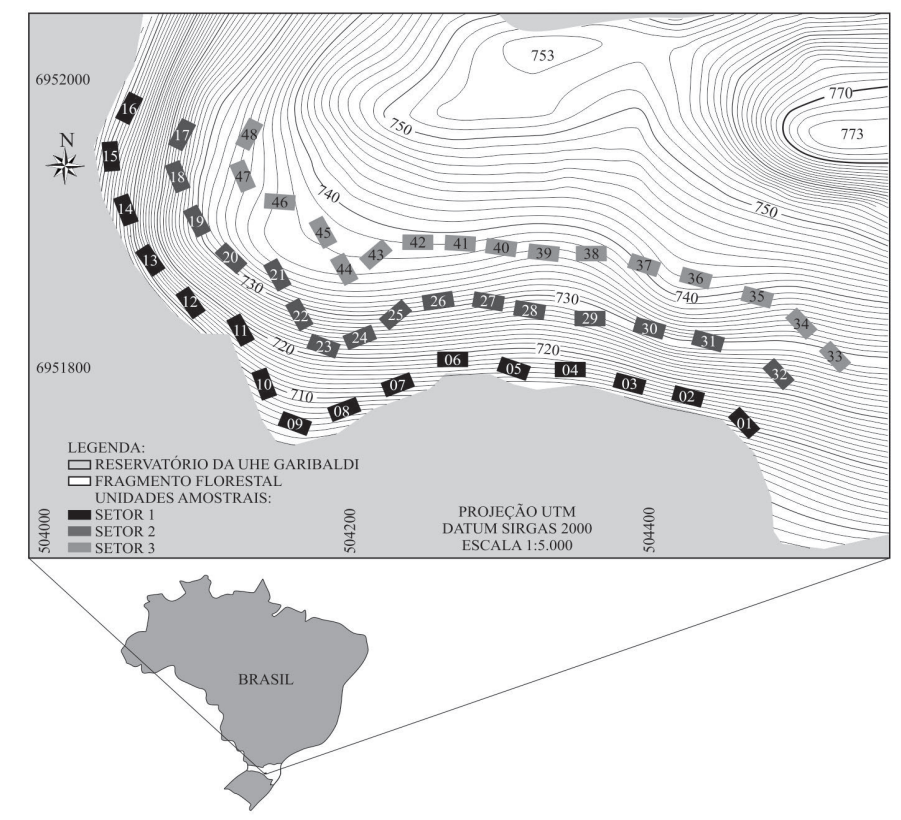

FIGURA 1: Localização das unidades amostrais no fragmento avaliado em São José do Cerrito-SC, com demonstração da topografia do terreno.

FIGURE 1: Sampling units location in the study forest fragment in the municipality of São José do Cerrito, SC state, with terrain topographic indication.

A UHE Garibaldi foi construída no ano de 2013, formando um lago de $26,79 \mathrm{~km}^{2}$ no Rio Canoas, o qual está inserido na Bacia Hidrográfica de mesmo nome. A cota (altitudinal) de inundação do lago, inicialmente autorizada pela ANEEL sem deplecionamento, foi de $705 \mathrm{~m}$, sendo o limite do nível maximorum estabelecido em 713 m (AGÊNCIA NACIONAL DE ENERGIA ELÉTRICA, 2010). Porém, no segundo semestre de 2014, devido à alta demanda de produção de energia no país, foi autorizado um ganho de utilização do reservatório, sendo considerada, desde então, a cota de geração a partir de $702,5 \mathrm{~m}$, permitindo um deplecionamento de $2,5 \mathrm{~m}$.

Um ano após o enchimento do reservatório, em 2014, o fragmento adjacente foi amostrado utilizandose 48 unidades amostrais de $200 \mathrm{~m}^{2}$ cada, as quais foram distribuídas de forma estratificada-sistemática, considerando três estratos, obedecendo à topografia do terreno: 16 parcelas adjacente à margem do reservatório, denominado setor inferior (S1), 16 no setor intermediário (S2), no meio da encosta, e 16 no setor superior (S3), no topo da encosta. As parcelas foram alocadas distantes $20 \mathrm{~m}$ entre si e $30 \mathrm{~m}$ entre os estratos. Cabe ressaltar que o setor inferior apresenta as menores cotas quando comparado com os demais. Apesar disso, possui considerável declividade em algumas parcelas, uma vez que fazia parte da encosta e que se tornou ambiente ciliar somente após o enchimento do reservatório. Assim, é o único setor com contato com a lâmina de água, sendo este contato regulado pela flutuação do nível do reservatório. Este nível pode ser alterado em um curto espaço de tempo de acordo com a geração de energia da UHE Garibaldi, ocasionando a submersão parcial ou até mesmo total do solo de algumas parcelas desse setor.

Nesse mesmo ano (2014), todos os indivíduos arbóreos dentro das parcelas com circunferência a altura do peito (CAP) $\geq 15,7 \mathrm{~cm}$ foram avaliados (identificados e mensurados), e dois anos após o enchimento do reservatório (2015), foi realizado o estudo de dinâmica, utilizando-se a mesma metodologia do primeiro inventário, com as árvores sobreviventes remedidas (CAP), as mortas - que não apresentavam condução de seiva - quantificadas, e as recrutas - aquelas que atingiram o CAP de $15,7 \mathrm{~cm}$ - incorporadas ao levantamento.

Nas mesmas parcelas foi realizado o levantamento das variáveis ambientais edáficas, topográficas, 
de abertura do dossel e de impacto ambiental. O levantamento das propriedades físico-químicas dos solos foi realizado por meio de amostras compostas, provenientes de nove coletas distribuídas sistematicamente em cada parcela, no perfil de 0 a $20 \mathrm{~cm}$ do solo. As análises dos solos foram realizadas na Universidade do Estado de Santa Catarina - UDESC. Foram quantificados o $\mathrm{pH}$, fósforo $(\mathrm{P})$, potássio $(\mathrm{K})$, cálcio $(\mathrm{Ca})$, magnésio

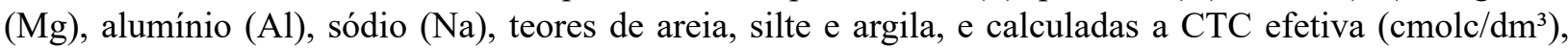
saturação por $\mathrm{Al}(\%)$, saturação de bases $\mathrm{V}(\%)$, índice $\mathrm{H}+\mathrm{Al}$, matéria orgânica (\%) e carbono orgânico (\%). O nível freático no solo foi avaliado por meio da instalação de poços de observação de $1 \mathrm{~m}$ de profundidade, alocados no centro das parcelas localizadas no setor inferior. Nos demais setores não foram instalados poços por se tratarem de áreas de encosta, distantes do reservatório em que não há nível freático próximo à superfície do solo. Os poços foram confeccionados segundo metodologia utilizada por Ivanauskas (2002), Barddal et al. (2004) e Silva, Higuchi e Van den Berg (2010): foram feitos de tubos de PVC de $50 \mathrm{~mm}$ de diâmetro por 1,20 m de comprimento e perfurados orifícios de $5 \mathrm{~mm}$ ao longo de todo o cumprimento de $1 \mathrm{~m}$, para permitir o escoamento da água para dentro do poço. Estes foram cobertos com tampa metálica para impedir a entrada de partículas. A medição do nível freático foi realizada a cada dois meses, durante um ano, com o auxílio de uma régua graduada, medindo-se desde a superfície do solo até o nível da lâmina d'água. Foram obtidos dados, por parcela, da média anual do nível freático no solo. A topografia do terreno foi obtida por meio da cota média, desnível máximo e declividade média (OLIVEIRA FILHO et al., 1994a) com o auxílio de trena, bússola, clinômetro e GPS (Sistema de Posicionamento Global). A cota média foi calculada como a média das cotas dos quatro vértices de cada parcela, o desnível máximo foi calculado pela diferença entre a maior e menor cota e a declividade média pela média das declividades dos quatro lados. Para verificar a abertura do dossel, foram realizadas observações da luminosidade, com o auxílio de um densiômetro esférico côncavo (LEMMON, 1956), por meio de quatro leituras nas direções dos lados das parcelas, sendo retirada a média das leituras por parcela. Os impactos ambientais foram avaliados por meio da observação de presença de trilhas, impactos causados pelo gado, marcas de fogo e corte seletivo de árvores dentro das parcelas, atribuindo-se para cada impacto notas de zero a cinco, sendo zero para ausência e cinco para o maior nível observado, conforme metodologia utilizada por Silva et al. (2009).

Foram calculadas as taxas demográficas para a comunidade e as populações. As taxas de mortalidade e recrutamento, assim como as de ganho e perda em área basal, com base no número de indivíduos e área basal, foram calculadas para a comunidade total, para a comunidade de cada setor e para cada população por meio dos modelos algébricos (LIEBERMAN et al., 1985; SHEIL; MAY, 1996; OLIVEIRA FILHO et al., 2007):

$$
\begin{aligned}
& M=\left\{1-\left[\left(\frac{N_{0}-m}{N_{0}}\right)\right]^{\frac{1}{t}}\right\} \times 100 \\
& R=\left[1-\left(1-\frac{r}{N_{t}}\right)^{\frac{1}{t}}\right] \times 100 \\
& P=\left\{1-\left[\frac{\left(A B_{0}-\left(A B_{m}+A B_{d}\right)\right)}{A B_{0}}\right]^{\frac{1}{t}}\right\} \times 100 \\
& G=\left\{1-\left[1-\left(\frac{A B_{r}+A B_{g}}{A B_{t}}\right)^{\frac{1}{t}}\right]\right\} \times 100
\end{aligned}
$$

Em que: $\mathrm{M}=$ taxa de mortalidade anual; $\mathrm{R}=$ taxa de recrutamento anual; $\mathrm{P}=$ taxa de perda em área basal anual; $\mathrm{G}=$ taxa de ganho em área basal anual; $\mathrm{t}=$ intervalo de tempo entre inventários; $\mathrm{N}_{\mathrm{o}}=$ número inicial de árvores; $\mathrm{N}_{\mathrm{t}}=$ número final de árvores depois de $\mathrm{t} ; \mathrm{m}=$ número de árvores mortas; $\mathrm{r}=$ número de árvores recrutadas; $\mathrm{AB}_{\mathrm{o}}=$ área basal inicial; $\mathrm{AB}_{\mathrm{t}}=$ área basal final depois de t; $\mathrm{AB}_{\mathrm{m}}=$ área basal das árvores mortas; $\mathrm{AB}_{\mathrm{d}}=$ perda em área basal (redução diamétrica e perda parcial de troncos); $\mathrm{AB}_{\mathrm{r}}=$ área basal de árvores recrutadas; $\mathrm{AB}_{\mathrm{g}}=$ ganho em área basal (crescimento das árvores).

As taxas de mudança líquida para o número de indivíduos $\left(\mathrm{Ch}_{\mathrm{N}}\right)$ e para a área basal $\left(\mathrm{Ch}_{\mathrm{AB}}\right)$ para toda a comunidade e de cada setor foram obtidas pelas equações, conforme Korning e Balslev (1994):

$$
\begin{aligned}
C h_{N} & =\left[\left(\frac{N_{t}}{N_{0}}\right)^{\frac{1}{t}}-1\right] \times 100 \\
C h_{A B} & =\left[\left(\frac{A B_{t}}{A B_{0}}\right)^{\frac{1}{t}}-1\right] \times 100
\end{aligned}
$$


A taxa média anual de rotatividade em número de indivíduos $\left(\mathrm{T}_{\mathrm{N}}\right)$ foi obtida para a comunidade total e de cada setor por meio da média das taxas de mortalidade e de recrutamento e a taxa média anual de rotatividade em área basal $\left(\mathrm{T}_{\mathrm{AB}}\right)$, também calculada para a comunidade total e de cada setor, foi obtida pela média de taxa de perda e taxa de ganho (OLIVEIRA FILHO; MELLO; SCOLFORO, 1997; WERNECK; FRANCESCHINELLI, 2004):

$$
\begin{aligned}
& T_{N}=\frac{M+R}{2} \\
& T_{A B}=\frac{P+G}{2}
\end{aligned}
$$

As taxas de dinâmica e as variáveis ambientais foram comparadas entre os setores (exceto nível freático nos solos, mensurado apenas no setor 1) por meio de análise de variância (ANOVA) para aquelas que, a partir do teste de Shapiro-Wilk, apresentaram distribuição normal. Taxas e variáveis com diferenças significativas entre os setores foram comparadas pelo teste de Tukey. Para as taxas e variáveis que não apresentaram normalidade, foi utilizado o teste de Kruskal-Wallis e, se detectado diferença, análise de comparação múltipla não-paramétrica.

Para ordenação das variáveis ambientais (exceto nível freático nos solos), foi aplicada a Análise de Componentes Principais (PCA). A influência de gradientes ambientais, sintetizados pelos eixos que explicam proporções significativas da inércia total da PCA, sobre as taxas demográficas da comunidade (mortalidade, recrutamento, ganho e perda em área basal), foi verificada por meio de modelos lineares generalizados considerando a distribuição binomial (regressão logística). A validação dos modelos se deu por meio da análise de resíduos (distribuição em função dos valores ajustados e das variáveis explicativas e dependência espacial) (ZUUR et al., 2009). As análises foram realizadas por meio da linguagem de programação estatística R (R CORE TEAM, 2016), junto com os pacotes Vegan (OKSANEN et al., 2016), NCF (BJORNSTAD, 2013) e Pgirmess (GIRAUDOUX, 2015).

\section{RESULTADOS E DISCUSSÃO}

Entre 2014 e 2015 não houve mudança na riqueza de espécies, sendo amostradas 70 espécies em ambos os anos. Dos 1.309 indivíduos vivos amostrados em 2014, 1.284 indivíduos sobreviveram e 25 indivíduos morreram (taxa de mortalidade $=1,91 \%$.ano ${ }^{-1}$ ). Com o recrutamento de 23 indivíduos (taxa de recrutamento $=1,76 \%$. ano ${ }^{-1}$ ), em 2015 foram observados 1.307 indivíduos. A taxa de mortalidade pouco superior ao recrutamento resultou em mudança líquida em número de indivíduos negativa, mas próxima de zero $\left(-0,15 \%\right.$.ano $\left.{ }^{-1}\right)$ (Tabela 1$)$. Porém, a taxa de ganho em área basal $\left(3,64 \%\right.$.ano $\left.{ }^{-1}\right)$ foi superior à de perda $\left(1,62 \%\right.$.ano $\left.\mathrm{o}^{-1}\right)$, resultando em valores positivos para a mudança líquida em área basal $(2,09 \%$.ano $\left.{ }^{1}\right)$ e rotatividade em área basal $\left(2,63 \% \cdot \mathrm{ano}^{-1}\right)$. Assim, sugere-se que a floresta esteja funcionando como um sumidouro de $\mathrm{CO}_{2}$, a partir do crescimento dos indivíduos sobreviventes. Esse padrão de acúmulo de biomassa tem sido encontrado em florestas da região (e.g. FORMENTO; SCHORN; RAMOS, 2004) e pode ser explicado como sendo um processo de recuperação pós-distúrbio das florestas que foram exploradas durante o corte da araucária, ocorrido especialmente nas décadas de 1950 a 1970. Salami et al. (2014), em FOM, também encontraram resultados similares de acúmulo de biomassa, porém, diferindo desse estudo, observaram maior recrutamento do que mortalidade. A maior mortalidade no presente caso pode estar relacionada a outros fatores, como o distúrbio mais recente de enchimento do reservatório. 
TABELA 1: Taxas de dinâmica por setor e para a comunidade de um remanescente florestal localizado em área de transição entre Floresta Ombrófila Mista e Floresta Estacional Decidual em São José do Cerrito-SC.

TABLE 1: Dynamics rates by sector and for the community in a forest remnant located in a transition area between Araucaria and Seasonal Decidual forests, in the municipality of São José de Cerrito, SC state.

\begin{tabular}{cccccc}
\hline Taxas & Setor 1 & Setor 2 & Setor 3 & $p$ & Comunidade \\
\hline $\mathrm{M}$ & 1,48 & 3,14 & 0,94 & $0,1990^{\mathrm{KW}}$ & 1,91 \\
$\mathrm{R}$ & 1,23 & 1,49 & 2,55 & $0,5154^{\mathrm{KW}}$ & 1,76 \\
$\mathrm{Ch}_{\mathrm{N}}$ & $-0,25$ & $-1,67$ & 1,65 & $0,4220^{\mathrm{AN}}$ & $-0,15$ \\
$\mathrm{~T}_{\mathrm{N}}$ & 1,36 & 2,31 & 1,74 & $0,4890^{\mathrm{KW}}$ & 1,83 \\
$\mathrm{G}$ & 2,71 & 3,5 & 4,47 & $0,1030^{\mathrm{AN}}$ & 3,64 \\
$\mathrm{P}$ & $2,51^{\mathrm{a}}$ & $1,33^{\mathrm{b}}$ & $1,16^{\mathrm{b}}$ & $0,0175^{\mathrm{KW}}$ & 1,62 \\
$\mathrm{Ch}_{\mathrm{AB}}$ & 0,21 & 2,25 & 3,46 & $0,0546^{\mathrm{AN}}$ & 2,09 \\
$\mathrm{~T}_{\mathrm{AB}}$ & $2,61^{\mathrm{ab}}$ & $2,42^{\mathrm{b}}$ & $2,82^{\mathrm{a}}$ & $0,0130^{\mathrm{KW}^{*}}$ & 2,63 \\
\hline
\end{tabular}

Em que: $\mathrm{M}=$ taxa de mortalidade; $\mathrm{R}=$ taxa de recrutamento; $\mathrm{Ch}_{\mathrm{N}}=$ mudança líquida em número de indivíduos; $\mathrm{T}_{\mathrm{N}}$ $=$ rotatividade em número de indivíduos; $\mathrm{G}=$ taxa de ganho em área basal; $\mathrm{P}=$ taxa de perda em área basal; $\mathrm{Ch}_{\mathrm{AB}}=$ mudança líquida em área basal; $\mathrm{T}_{\mathrm{AB}}=$ rotatividade em área basal. Todas as taxas estão em $\%$.ano ${ }^{-1} \cdot p=$ significância pela ANOVA ( ${ }^{\mathrm{AN}}$, distribuição normal) ou Kruskal-Wallis ( ${ }^{\mathrm{KW}}$, não normal), sendo ${ }^{*}$ as taxas significativas a $95 \%$ de confiança. Valores seguidos pela mesma letra indicam ausência de diferenças significativas pela análise de comparação múltipla (não paramétrica).

Quando se observam as taxas de dinâmica separadas por setor, é possível perceber o mesmo padrão para os setores 1 e 2 , com taxas de mortalidade $\left(1,48 \%\right.$. ano ${ }^{-1}$ e $3,14 \%$. ano $^{-1}$, respectivamente) superiores às de recrutamento $\left(1,23 \%\right.$.ano ${ }^{-1}$ e $1,49 \%$.ano ${ }^{-1}$, respectivamente $)$ e com ganhos em área basal $(2,71 \%$.ano${ }^{1}$ e $3,50 \%$. ano ${ }^{-1}$, respectivamente) superiores às perdas $\left(2,51 \%\right.$.ano ${ }^{-1}$ e $1,33 \%$.ano ${ }^{-1}$, respectivamente). No setor 1, a maior mortalidade pode ser explicada pelo contato desse com a água do reservatório, enquanto a alta taxa de mortalidade no setor 2 pode estar relacionada ao aumento de maciços do bambu Merostachys sp. em grande parte das parcelas desse setor, sendo que nos demais setores sua abundância é menor. Essa elevada abundância dos maciços de bambu no setor 2 resultou no reduzido número de árvores por parcela (de oito a 20 indivíduos), sendo que outros autores (OLIVEIRA FILHO et al., 1994b; GUILHERME et al., 2004; BUDKE et al., 2010; SANTOS et al., 2015) também já observaram sua interferência negativa na diversidade, composição florística, estrutura e dinâmica florestal. A presença dos maciços de bambu pode estar relacionada a um efeito secundário do corte seletivo que ocorreu especialmente na área na década de 1970.

No setor 3 foi observado padrão distinto, com taxa de recrutamento $\left(2,55 \%\right.$.ano $\left.{ }^{-1}\right)$ maior que a de mortalidade $\left(0,94 \%\right.$.ano $\left.{ }^{-1}\right)$, resultando em mudança líquida positiva em número de indivíduos $(1,65 \%$.ano ${ }^{1}$ ). A reduzida mortalidade nesse setor pode ser explicada pelo baixo impacto observado, em comparação com os demais setores, nos quais foi observado contato com a lâmina de água e maciços de bambu mais densos.

Apesar desse padrão geral para cada setor, observa-se que, quando comparadas as taxas entre os setores, não houve diferenças estatísticas $(p>0,05)$ para aquelas relacionadas ao número de indivíduos (mortalidade, recrutamento, mudança líquida e rotatividade) e ao ganho e mudança líquida em área basal. A ausência de significância para essas taxas ocorreu, também, pelos valores serem muito variáveis entre as 
parcelas, indicando elevada heterogeneidade dentro de cada setor. Contudo, a distinção dos padrões gerais entre os setores pode ser confirmada quando se comparam os valores das outras taxas de mudanças em área basal, com a maior perda no setor $1\left(2,51 \% \cdot\right.$ ano $\left.^{-1}\right)(p=0,0175)$, sendo esse valor muito próximo ao de ganho nesse setor $\left(2,71 \%\right.$.ano $\left.{ }^{-1}\right)$, resultando em mudança líquida em área basal de apenas $0,21 \%$.ano ${ }^{-1}$. Nos demais setores, os valores de perda e ganho foram distintos, o que resultou em taxas superiores de mudanças líquidas em área basal $\left(\mathrm{Ch}_{\mathrm{AB}}\right.$ setor $3=3,46 \%$. ano ${ }^{-1} \mathrm{e} \mathrm{Ch}_{\mathrm{AB}}$ setor $2=2,25 \%$. ano $\left.{ }^{-1}\right)$. Isso indica que, no setor 1, as árvores sobreviventes podem estar crescendo menos e ocorrendo a mortalidade de árvores de maior porte. Mesmo com baixa mortalidade nesse setor, a mortalidade de poucas árvores de grande porte pode resultar em elevada perda em área basal. Esse padrão pode estar indicando, nesse setor, a influência negativa da lâmina de água do reservatório na floresta.

Assim, valores de ganho e perda em área basal muito próximos podem indicar estabilidade no desenvolvimento da floresta e é comum em áreas inundáveis, uma vez que espécies expostas ao alagamento podem desenvolver estratégias de sobrevivência, como a estabilização do crescimento devido ao encharcamento do solo ou à redução do crescimento de alguns órgãos para economizar energia e manter o funcionamento mínimo de seu metabolismo (WIEDENROTH, 1993; ARMSTRONG; BRAENDLE; JACKSON, 1994; SILVA et al., 2012). Nesse sentido, pode-se destacar como exemplo de estratégia de sobrevivência a Sebastiania commersoniana (Baill.) L.B. Sm. \& Downs, a qual se mantém estável sob alagamento, sugerindo que a espécie é capaz de sobreviver em condições de baixa concentração de oxigênio devido às adaptações morfoanatômica e fisiológica (KOLB et al., 1998). De acordo com Kanieski (2013), a espécie tem ampla plasticidade na sua ocorrência, podendo ser encontrada tanto em áreas de boa drenagem, como em áreas de saturação hídrica, porém, são normalmente abundantes em área aluviais, conforme também observado por Silva et al. (2007).

Dessa forma, quando se observam as taxas demográficas das 10 espécies de maior densidade em 2015 (Tabela 2), espera-se encontrar Sebastiania commersoniana bem representada na estrutura da floresta, uma vez que o contato da área de estudo com a vegetação ciliar previamente existente pode ter favorecido um elevado compartilhamento de espécies arbóreas com elevada plasticidade ecológica. De fato, esta ocorre entre as 10 espécies mais comuns em todos os setores, os quais geralmente apresentam aumento em número de indivíduos e em área basal, exceto no setor 1. Nesse setor, houve estabilidade no número de indivíduos e pequena perda em área basal. Kanieski (2013), em estudo em um fragmento de FOM Aluvial no município de Araucária-PR, o qual foi impactado por derramamento de petróleo e alagado devido à construção de diques na tentativa de descontaminação, observou que o incremento diamétrico de Sebastiania commersoniana reduziu ao longo dos anos com a saturação hídrica permanente, confirmando que esta, sob saturação hídrica, pode reduzir seu crescimento.

TABELA 2: Taxas de dinâmica das dez espécies de maior densidade em 2015 por setor (S1, S2 e S3) e para a comunidade $(\mathrm{Com})$ de um remanescente florestal localizado em área de transição entre Floresta Ombrófila Mista e Floresta Estacional Decidual em São José do Cerrito-SC.

TABLE 2: Dynamics rates for the top ten most abundant species in 2015 by sectors (S1, S2 and S3) and for the community (Com) of a forest remnant located in a transition area between Araucaria and Seasonal Decidual forests in the municipallity of São José do Cerrito, SC state.

\begin{tabular}{cccccccccccc}
\hline \multirow{2}{*}{ Setores } & Espécies & $\begin{array}{c}\text { N. de } \\
\text { indivíduos }\end{array}$ & \multicolumn{7}{c}{$\begin{array}{c}\text { Área } \\
\text { Basal }\end{array}$} \\
\cline { 2 - 10 } & \multicolumn{1}{c}{$\mathrm{N}_{1}$} & $\mathrm{~N}_{2}$ & $\mathrm{M}$ & $\mathrm{R}$ & $\mathrm{AB}_{1}$ & $\mathrm{AB}_{2}$ & $\mathrm{G}$ & $\mathrm{P}$ \\
\hline S1 & $\begin{array}{c}\text { Allophylus edulis (A.St.-Hil. et al.) } \\
\text { Hieron. ex Niederl. }\end{array}$ & 92 & 94 & 1,09 & 3,19 & 0,807 & 0,819 & 4,83 & 3,45 \\
& $\begin{array}{c}\text { Nectandra megapotamica (Spreng.) } \\
\text { Mez } \\
\text { Araucaria angustifolia (Bertol.) } \\
\text { Kuntze }\end{array}$ & 45 & 45 & 0 & 0 & 0,770 & 0,787 & 3,57 & 1,45 \\
& 31 & 31 & 0 & 0 & 1,565 & 1,582 & 2,06 & 1 \\
\hline
\end{tabular}


TABELA 2: Continuação...

TABLE 2: Continued..

\begin{tabular}{|c|c|c|c|c|c|c|c|c|c|}
\hline \multirow[t]{8}{*}{ Setores } & \multirow[t]{2}{*}{ Espécies } & \multicolumn{4}{|l|}{$\begin{array}{c}\text { N. de } \\
\text { indivíduos }\end{array}$} & \multicolumn{4}{|l|}{$\begin{array}{l}\text { Área } \\
\text { Basal }\end{array}$} \\
\hline & & $\mathrm{N}_{1}$ & $\mathrm{~N}_{2}$ & M & $\mathrm{R}$ & $\mathrm{AB}_{1}$ & $\mathrm{AB}_{2}$ & G & $\mathrm{P}$ \\
\hline & Styrax leprosus Hook. \& Arn. & 22 & 21 & 4,55 & 0 & 0,197 & 0,186 & 0,97 & 6,51 \\
\hline & Casearia decandra Jacq. & 21 & 21 & 0 & 0 & 0,155 & 0,151 & 2,02 & 4,64 \\
\hline & $\begin{array}{c}\text { Ocotea pulchella (Nees \& Mart.) } \\
\text { Mez }\end{array}$ & 16 & 16 & 0 & 0 & 0,074 & 0,065 & 0,45 & 12,53 \\
\hline & $\begin{array}{l}\text { Sebastiania commersoniana (Baill.) } \\
\text { L.B. Sm. \& Downs }\end{array}$ & 16 & 16 & 0 & 0 & 0,459 & 0,447 & 0,82 & 3,36 \\
\hline & $\begin{array}{c}\text { Muellera campestris (Mart. ex } \\
\text { Benth.) M.J. Silva \& A.M.G. } \\
\text { Azevedo }\end{array}$ & 13 & 13 & 0 & 0 & 0,205 & 0,209 & 3 & 1,1 \\
\hline & Sapium glandulosum (L.) Morong & 7 & 7 & 0 & 0 & 0,230 & 0,232 & 2,44 & 1,5 \\
\hline Total S1 & & 406 & 405 & 1,48 & 1,23 & 7,816 & 7,832 & 2,71 & 2,51 \\
\hline \multirow[t]{10}{*}{$\mathrm{S} 2$} & Allophylus edulis & 130 & 129 & 2,31 & 1,55 & 1,13 & 1,142 & 4,37 & 3,35 \\
\hline & Styrax leprosus & 53 & 52 & 5,66 & 3,85 & 0,471 & 0,481 & 5,63 & 3,64 \\
\hline & Nectandra megapotamica & 45 & 45 & 2,22 & 2,22 & 0,903 & 0,960 & 6,36 & 0,52 \\
\hline & Araucaria angustifolia & 31 & 32 & 0 & 3,13 & 0,840 & 0,873 & 3,88 & 0 \\
\hline & Cupania vernalis & 25 & 25 & 0 & 0 & 0,688 & 0,702 & 1,92 & 0 \\
\hline & Sebastiania commersoniana & 18 & 19 & 0 & 5,26 & 0,506 & 0,515 & 2,06 & 0,39 \\
\hline & Casearia decandra & 18 & 17 & 5,56 & 0 & 0,311 & 0,311 & 2,14 & 2,06 \\
\hline & Erythroxylum deciduum A.St.-Hil. & 14 & 14 & 0 & 0 & 0,292 & 0,301 & 3,02 & 0 \\
\hline & Muellera campestris & 14 & 14 & 0 & 0 & 0,370 & 0,373 & 1,03 & 0,21 \\
\hline & Mimosa scabrella Benth. & 14 & 13 & 7,14 & 0 & 0,058 & 0,055 & 16,44 & 19,51 \\
\hline Total S2 & & 478 & 470 & 3,14 & 1,49 & 8,343 & 8,531 & 3,5 & 1,33 \\
\hline \multirow[t]{9}{*}{ S3 } & Allophylus edulis & 98 & 98 & 1,02 & 1,02 & 0,663 & 0,675 & 4,18 & 2,47 \\
\hline & Styrax leprosus & 59 & 59 & 0 & 0 & 0,863 & 0,896 & 4,33 & 0,65 \\
\hline & Nectandra megapotamica & 36 & 37 & 0 & 2,7 & 1,063 & 1,119 & 4,98 & 0,01 \\
\hline & Araucaria angustifolia & 27 & 27 & 0 & 0 & 0,958 & 1,009 & 5,01 & 0 \\
\hline & Casearia decandra & 24 & 24 & 4,17 & 4,17 & 0,220 & 0,224 & 3,81 & 2,35 \\
\hline & Sebastiania commersoniana & 20 & 21 & 0 & 4,76 & 0,637 & 0,650 & 2,72 & 0,73 \\
\hline & Cupania vernalis & 13 & 14. & 7,69 & 14,29 & 0,298 & 0,278 & 3,52 & 9,91 \\
\hline & Luehea divaricata Mart. \& Zucc. & 11 & 11 & 0 & 0 & 0,488 & 0,516 & 5,55 & 0 \\
\hline & $\begin{array}{c}\text { Annona rugulosa (Schltdl.) } \\
\text { H.Rainer } \\
\end{array}$ & 7 & 7 & 0 & 0 & 0,054 & 0,059 & 9,69 & 0 \\
\hline Total S3 & & 425 & 432 & 0,94 & 2,55 & 9,806 & 10,145 & 4,47 & 1,16 \\
\hline \multirow[t]{4}{*}{ Com } & Allophylus edulis & 320 & 321 & 1,56 & 1,87 & 2,600 & 2,636 & 4,46 & 3,16 \\
\hline & Styrax leprosus & 134 & 132 & 2,99 & 1,52 & 1,530 & 1,562 & 4,33 & 2,32 \\
\hline & Nectandra megapotamica & 126 & 127 & 0,79 & 1,57 & 2,737 & 2,866 & 5,05 & 0,58 \\
\hline & Araucaria angustifolia & 89 & 90 & 0 & 1,11 & 3,363 & 3,464 & 3,38 & 0,47 \\
\hline
\end{tabular}


TABELA 2: Continuação...

TABLE 2: Continued...

\begin{tabular}{|c|c|c|c|c|c|c|c|c|c|}
\hline \multirow[t]{2}{*}{ Setores } & \multirow[t]{2}{*}{ Espécies } & \multicolumn{4}{|l|}{$\begin{array}{c}\text { N. de } \\
\text { indivíduos }\end{array}$} & \multicolumn{4}{|l|}{$\begin{array}{l}\text { Área } \\
\text { Basal }\end{array}$} \\
\hline & & $\mathrm{N}_{1}$ & $\mathrm{~N}_{2}$ & $\mathrm{M}$ & $\mathrm{R}$ & $\mathrm{AB}_{1}$ & $\mathrm{AB}_{2}$ & G & $\mathrm{P}$ \\
\hline & Casearia decandra & 63 & 62 & 3,17 & 1,61 & 0,686 & 0,686 & 2,66 & 2,74 \\
\hline & Sebastiania commersoniana & 54 & 56 & 0 & 3,57 & 1,601 & 1,611 & 1,98 & 1,38 \\
\hline & Muellera campestris & 34 & 34 & 0 & 0 & 0,634 & 0,641 & 1,6 & 0,48 \\
\hline & Annona rugulosa & 24 & 23 & 4,17 & 0 & 0,164 & 0,168 & 5,23 & 3,06 \\
\hline & Ocotea pulchella & 24 & 24 & 0 & 0 & 0,442 & 0,457 & 5,27 & 2,11 \\
\hline $\begin{array}{c}\text { Total } \\
\text { Comunidade }\end{array}$ & & 1309 & 1307 & 1,91 & 1,76 & 25,96 & 26,508 & 3,64 & 1,62 \\
\hline
\end{tabular}

Em que: $\mathrm{N}_{1}=$ número de indivíduos em 2014; $\mathrm{N}_{2}=$ número de indivíduos em 2015; $\mathrm{M}=$ taxa de mortalidade, em $\%$.ano ${ }^{-1} ; \mathrm{R}=$ taxa de recrutamento, em \%.ano ${ }^{-1} ; \mathrm{AB}_{1}=$ área basal em 2014, em m² $\mathrm{AB}_{2}=$ área basal em 2015, em m²; $\mathrm{G}=$ taxa de ganho em área basal, em \%.ano ${ }^{-1} ; \mathrm{P}=$ taxa de perda em área basal, em \%.ano ${ }^{-1}$.

Entre as 10 espécies de maior densidade, é possível verificar, também, algumas que tiveram ganho em todos os setores. Allophylus edulis, por exemplo, a espécie de maior densidade em todos os setores, obteve tendência de estabilidade em número de indivíduos, provavelmente devido ao curto período de avaliação, entretanto, com maior ganho $\left(4,46 \%\right.$.ano $\left.{ }^{-1}\right)$ do que perda $\left(3,16 \%\right.$.ano $\left.{ }^{-1}\right)$, considerando toda a comunidade. Essa espécie já foi relatada em outros estudos como espécie tolerante a áreas inundáveis no sul do Brasil (BARDALL et al., 2004; SILVA et al., 2007). Além disso, Allophylus edulis apresenta alta produção de frutos, que são dispersos de forma zoocórica, o que, aliada às características ecológicas da espécie, explica sua alta densidade na área.

Outras espécies podem ser destacadas, como Ocotea pulchella, com elevada perda em área basal no setor $1\left(12,53 \%\right.$.ano $\left.{ }^{-1}\right)$. Essas perdas de algumas espécies sem ocorrência de mortalidade podem ser explicadas devido à estabilização do crescimento, ocorrido em função do encharcamento do solo, seguido por processo de senescência, ou, nesse caso em especial, pela perda de troncos bifurcados, sem a mortalidade da árvore. Spathelf et al. (2000), em estudo do incremento em diâmetro do tronco de Ocotea pulchella em uma área às margens de uma barragem no Rio Grande do Sul, concluíram que o excesso de água resultou na redução do crescimento diamétrico das árvores. No entanto, espécies mais tolerantes, como Nectandra megapotamica, por exemplo, apresentaram maiores ganhos que perdas, inclusive no setor 1 . Botrel et al. (2002) e Bianchini et al. (2003) já haviam relatado essa espécie como tolerante ao alagamento e de ocorrência comum no ambiente ripário.

Em relação às variáveis ambientais mensuradas na área (Tabela 3), de acordo com a classificação proposta por Alvarez et al. (1999), o solo apresenta acidez elevada, uma vez que o pH médio em água apresentou valor baixo $(4,58)$. A saturação por bases, que é composta pelos nutrientes minerais e indica a fertilidade do solo, pode ser considerada baixa, com valores inferiores a 50\% (V=34,98\%), indicando um solo distrófico, de acordo com a classificação da EMBRAPA (2010). Embora a área tenha apresentado elevada acidez e baixa fertilidade, de acordo com Alvarez et al. (1999), a matéria orgânica presente na área apresenta um nível alto (5,99\%), embora seja menor quando comparado com outros estudos realizados na região (e.g. HIGUCHI et al., 2012; MARCON et al., 2014). Quanto à textura dos solos da área de estudo, de acordo com a classificação da EMBRAPA (2006), esta pode ser considerada média, uma vez que houve menos de $35 \%$ de argila e mais de $15 \%$ de areia. O relevo da área, de acordo com a classificação proposta por Souza (2007), pode ser considerado ondulado com declives acentuados $\left(11,67^{\circ}\right)$. A abertura do dossel para a comunidade pode ser considerada baixa $(8,35 \%)$, refletindo em uma cobertura elevada $(91,65 \%)$ quando comparada com outros estudos em fragmentos de Floresta Ombrófila Mista (e.g. HIGUCHI et al., 2012, encontraram valor de 87,20\%). Em relação aos impactos ambientais, estes também podem ser considerados baixos, visto que estão com valores próximos de zero. 
TABELA 3: Valores médios (Me) máximos (Ma) e mínimos (Mi) das variáveis ambientais mensuradas nas parcelas dos setores (S1, S2 e S3) e toda a comunidade (Com) de um remanescente florestal localizado em área de transição entre Floresta Ombrófila Mista e Floresta Estacional Decidual em São José do Cerrito-SC.

TABLE 3: $\quad$ Mean (Me), maximum (Ma) and minimum (Mi) values of measured environmental variables in sectors (S1, S2 and S3) and whole area (Com) plots of a forest remnant located in a transition area between Araucaria and Seasonal Decidual forests, in the municipallity of São José do Cerrito, SC state.

\begin{tabular}{|c|c|c|c|c|c|c|c|c|}
\hline \multirow{2}{*}{$\begin{array}{l}\text { Variáveis } \\
\text { ambientais }\end{array}$} & \multicolumn{2}{|r|}{ S1 } & \multicolumn{2}{|r|}{$\mathrm{S} 2$} & \multicolumn{2}{|r|}{ S3 } & \multirow[t]{2}{*}{$p$} & \multirow{2}{*}{$\begin{array}{c}\text { Com } \\
\mathrm{Me}\end{array}$} \\
\hline & $\mathrm{Me}$ & $\mathrm{Ma} / \mathrm{Mi}$ & $\mathrm{Me}$ & $\mathrm{Ma} / \mathrm{Mi}$ & $\mathrm{Me}$ & $\mathrm{Ma} / \mathrm{Mi}$ & & \\
\hline Areia (\%) & 22,44 & $29 / 17$ & 22,88 & $39 / 16$ & 23,75 & $31 / 15$ & $0,4705^{\mathrm{KW}}$ & 23,02 \\
\hline Silte $(\%)$ & 43,69 & $54 / 32$ & 42,19 & $54 / 35$ & 40,75 & $48 / 36$ & $0,6477^{\mathrm{KW}}$ & 42,21 \\
\hline Argila (\%) & 34 & $44 / 22$ & 35 & $47 / 17$ & 35,56 & $43 / 27$ & $0,8896^{\mathrm{KW}}$ & 34,85 \\
\hline $\mathrm{pH} \mathrm{H}_{2} \mathrm{O}(1: 1)$ & 4,48 & $5,6 / 3,8$ & 4,61 & $5,8 / 4$ & 4,66 & $5,3 / 4,4$ & $0,1885^{\mathrm{KW}}$ & 4,58 \\
\hline $\mathrm{Ca}\left(\mathrm{cmolc} / \mathrm{dm}^{3}\right)$ & 4,93 & $11,81 / 1,81$ & 4,48 & $10,48 / 1,18$ & 4,4 & $7,72 / 2,88$ & $0,3465 \mathrm{KW}$ & 4,6 \\
\hline $\begin{array}{l}\mathrm{Mg}(\mathrm{cmolc} / \\
\left.\mathrm{dm}^{3}\right)\end{array}$ & 3,09 & $6,22 / 1,49$ & 3,41 & $7,35 / 1,32$ & 3,58 & $4,53 / 2,5$ & $0,2000^{\mathrm{KW}}$ & 3,36 \\
\hline $\mathrm{Al}\left(\mathrm{cmolc} / \mathrm{dm}^{3}\right)$ & 2,34 & $5,54 / 0,22$ & 2,08 & $4,17 / 0$ & 1,47 & $2,51 / 0,47$ & $0,3404^{\mathrm{KW}}$ & 1,96 \\
\hline $\begin{array}{c}\mathrm{H}+\mathrm{Al}(\mathrm{cmolc} / \\
\left.\mathrm{dm}^{3}\right)\end{array}$ & 20,21 & $38,6 / 3,9$ & 19,43 & $34,5 / 4,9$ & 16,87 & $27,4 / 6,2$ & $0,6596^{\mathrm{KW}}$ & 18,83 \\
\hline $\begin{array}{l}\text { CTC efetiva } \\
\left(\mathrm{cmolc} / \mathrm{dm}^{3}\right)\end{array}$ & 10,63 & $18,69 / 6,7$ & 10,2 & $17,16 / 6,77$ & 9,5 & $12,54 / 7,54$ & $0,9902^{\mathrm{KW}}$ & 10,11 \\
\hline $\mathrm{SAl}(\%)$ & 27,61 & $61,62 / 1,28$ & 24,59 & $61,6 / 0$ & 15,96 & $27,88 / 4,23$ & $0,3225^{\mathrm{KW}}$ & 22,72 \\
\hline M.O. (\%) & 5,84 & $7,5 / 4,4$ & 6,04 & $8,3 / 4,3$ & 6,1 & $7,3 / 5,1$ & $0,6940^{\mathrm{AN}}$ & 5,99 \\
\hline C.O. $(\%)$ & 3,39 & $4,35 / 2,67$ & 3,75 & $7,54 / 2,49$ & 3,54 & $4,23 / 2,96$ & $0,7074^{\mathrm{KW}}$ & 3,56 \\
\hline $\mathrm{P}\left(\mathrm{mg} / \mathrm{dm}^{3}\right)$ & $2,68^{\mathrm{b}}$ & $3,9 / 1$ & $2,98^{b}$ & $3,7 / 2,4$ & $3,98^{\mathrm{a}}$ & $7,5 / 2,9$ & $0,0002^{\mathrm{KW}}$ & 3,21 \\
\hline $\mathrm{Na}\left(\mathrm{mg} / \mathrm{dm}^{3}\right)$ & $11,81^{\mathrm{a}}$ & 19-Jul & $7,94^{b}$ & 11-May & $8,88^{b}$ & 10-Jul & $3,503^{\mathrm{e}-05 \mathrm{KW}}$ & 9,54 \\
\hline $\mathrm{K}\left(\mathrm{mg} / \mathrm{dm}^{3}\right)$ & 104,19 & $223 / 40$ & 91,81 & $237 / 37$ & 72,94 & $123 / 42$ & $0,6634^{\mathrm{KW}}$ & 89,65 \\
\hline
\end{tabular}


TABELA 3: Continuação...

TABLE 3: Continued...

\begin{tabular}{|c|c|c|c|c|c|c|c|c|}
\hline \multirow{2}{*}{$\begin{array}{l}\text { Variáveis } \\
\text { ambientais }\end{array}$} & \multicolumn{2}{|r|}{ S1 } & \multicolumn{2}{|r|}{$\mathrm{S} 2$} & \multicolumn{2}{|r|}{ S3 } & \multirow[t]{2}{*}{$p$} & \multirow{2}{*}{$\begin{array}{c}\text { Com } \\
\mathrm{Me}\end{array}$} \\
\hline & $\mathrm{Me}$ & $\mathrm{Ma} / \mathrm{Mi}$ & $\mathrm{Me}$ & $\mathrm{Ma} / \mathrm{Mi}$ & $\mathrm{Me}$ & $\mathrm{Ma} / \mathrm{Mi}$ & & \\
\hline Cota (m) & $721,54^{b}$ & $28,98 / 712,24$ & $743,36^{\mathrm{a}}$ & $756,11 / 733,97$ & $749,59^{\mathrm{a}}$ & $759,93 / 740,09$ & $3,728^{\mathrm{e}-08 \mathrm{KW}}$ & 738,16 \\
\hline Des.Max (m) & 4,3 & $11,39 / 1,74$ & 4,67 & $10,08 / 1,91$ & 4,45 & $6,99 / 0,52$ & $0,6754 \mathrm{KW}$ & 4,47 \\
\hline $\begin{array}{c}\text { Abert. Dossel } \\
(\%)\end{array}$ & $6,04^{b}$ & $8,6 / 4$ & $7,81^{\mathrm{b}}$ & $10,6 / 5,8$ & $11,21^{\mathrm{a}}$ & $13 / 9,4$ & $3,565^{\mathrm{e}-08 \mathrm{KW}}$ & 8,35 \\
\hline Nível F. (m) & $-0,09$ & $0,0 /-0,74$ & - & - & - & - & - & - \\
\hline Imp. Amb. & $0,56^{\mathrm{a}}$ & $1 / 0,5$ & $0,30^{\mathrm{b}}$ & $1 / 0,25$ & $0,39^{\mathrm{b}}$ & $0,75 / 0,25$ & $1,422^{\mathrm{e}-05 \mathrm{KW}}$ & 0,42 \\
\hline
\end{tabular}

Em que: Areia = teor de areia; Silte = teor de silte; Argila = teor de argila; $\mathrm{pH} \mathrm{H}_{2} \mathrm{O}=\mathrm{pH}$ em água; $\mathrm{Ca}=$ cálcio; $\mathrm{Mg}=$ magnésio; $\mathrm{Al}=$ alumínio; $\mathrm{H}+\mathrm{Al}$ = hidrogênio mais alumínio; $\mathrm{CTC}$ efetiva = capacidade de troca de cátions efetiva; Sal = saturação por alumínio; SatBases = saturação por bases; M.O. = matéria orgânica; C.O. = carbono orgânico; P= fósforo; $\mathrm{Na}$ = sódio; $\mathrm{K}$ = potássio; Dec.Med = declividade média; $\mathrm{Cota}=$ cota média; Des.Max = desnível máximo; Abert. Dossel $=$ abertura de dossel; Nível F. = nível freático no solo; Imp. Amb. = impacto ambiental; $p=$ significância pela ANOVA ( ${ }^{\mathrm{AN}}$, distribuição normal) ou Kruskal-Wallis ( ${ }^{\mathrm{KW}}$, não normal). Valores seguidos pela mesma letra indicam ausência de diferenças significativas pela análise de comparação múltipla (não paramétrica).

Quando as variáveis ambientais são comparadas entre os setores, somente o fósforo $(\mathrm{P})$, sódio $(\mathrm{Na})$, cota, abertura do dossel e impacto ambiental apresentaram diferenças. O teor de $\mathrm{P}$ e a abertura do dossel foram maiores no setor 3. A maior abertura do dossel nesse setor pode ser explicada pela presença de clareiras observadas a campo, provocadas, principalmente, pela mortalidade de indivíduos de grande porte no passado. A maior entrada de luz nesse setor, associada à maior disponibilidade de $\mathrm{P}$ quando comparado aos demais setores, também explica porque esse é o único setor que apresentou maior recrutamento do que mortalidade, já que essas duas variáveis podem estimular o crescimento das plantas, o que indica estágio silvigenético distinto dos demais, que passaram por distúrbios mais recentes (enchimento do reservatório no setor 1 e abundância de bambu no setor 2).

Já a cota foi menor no setor 1 , por ser o local mais baixo, sendo os demais setores localizados na encosta, em maior altitude. $\mathrm{O}$ impacto ambiental, maior no setor 1 , pode ser explicado por ser a área mais próxima ao rio, provavelmente de maior trânsito de pessoas (e.g., pescadores). De fato, foram observados indícios de cortes seletivos nesse setor, os quais ocorreram anteriormente ao período de estudo, portanto, não influenciando a taxa de mortalidade observada. O teor de Na também foi maior no setor 1 , o que pode estar relacionado à flutuação do nível da lâmina d'água nesse setor. Os sais presentes nos solos podem ser carreados para horizontes inferiores, por meio da percolação (OLIVEIRA; GOMES FILHO; ENÉAS FILHO, 2010), mas, à medida que a água é evaporada, principalmente quando o nível freático tem movimento de subida e descida próximo à superfície do solo, ocorre o acúmulo de sais nas camadas superiores do perfil (AYERS; WESTCOT, 1991). Portanto, pode-se inferir que o maior teor de Na no setor 1 está relacionado à evaporação da água no solo, decorrente da flutuação do nível do reservatório, embora, durante o ano de avaliação, somente uma parcela (de número 2) apresentou nível freático acima da superfície do solo neste setor. Parte desse resultado pode ser explicado pelo fato de haver $2 \mathrm{~m}$ de deplecionamento da lâmina de água, expondo o setor 1 a diferentes níveis do reservatório em curtos espaços temporais. Dessa forma, não foi possível observar, em avaliações realizadas em períodos de dois meses, a água superficial com maior 
frequência. Mesmo assim, foi possível observar, pela presença de água nos poços de medição em 37,5\% das parcelas (6/16), que há influência deste nível freático sobre as raízes das árvores, o que reforça a hipótese de que a lâmina de água está influenciando as taxas de dinâmica no setor 1 .

A variação explicada pelos eixos 1 e 2 da PCA (Figura 2) representou uma proporção significativa da inércia total dos dados, indicada pela análise de scree plot, na qual o eixo 1 sintetizou $44,00 \%$ do total das variáveis ambientais mensuradas e o eixo $2,17,00 \%$, explicando uma variação total de $61,00 \%$. Observase, no gráfico, um gradiente de fertilidade no eixo 1 e um gradiente associado, principalmente, à topografia e à abertura do dossel no eixo 2. As variáveis com os maiores valores de correlação com o Eixo 1 foram saturação por bases $(0,32), \mathrm{Ca}(0,32)$ e $\mathrm{pH}(0,31)$. Com o Eixo 2 apresentaram maiores correlações as variáveis cota $(-0,41)$, declividade média $(-0,35)$ e abertura do dossel $(-0,34)$. A setorização da distribuição das parcelas, definida em função do relevo, apresentou relação apenas com o eixo 2, o que era esperado, uma vez que este eixo tem elevada correlação com variáveis topográficas. Por outro lado, a não associação da setorização com o eixo 1 da PCA demonstra que as parcelas de todos os setores apresentam elevada heterogeneidade quanto ao gradiente de fertilidade.

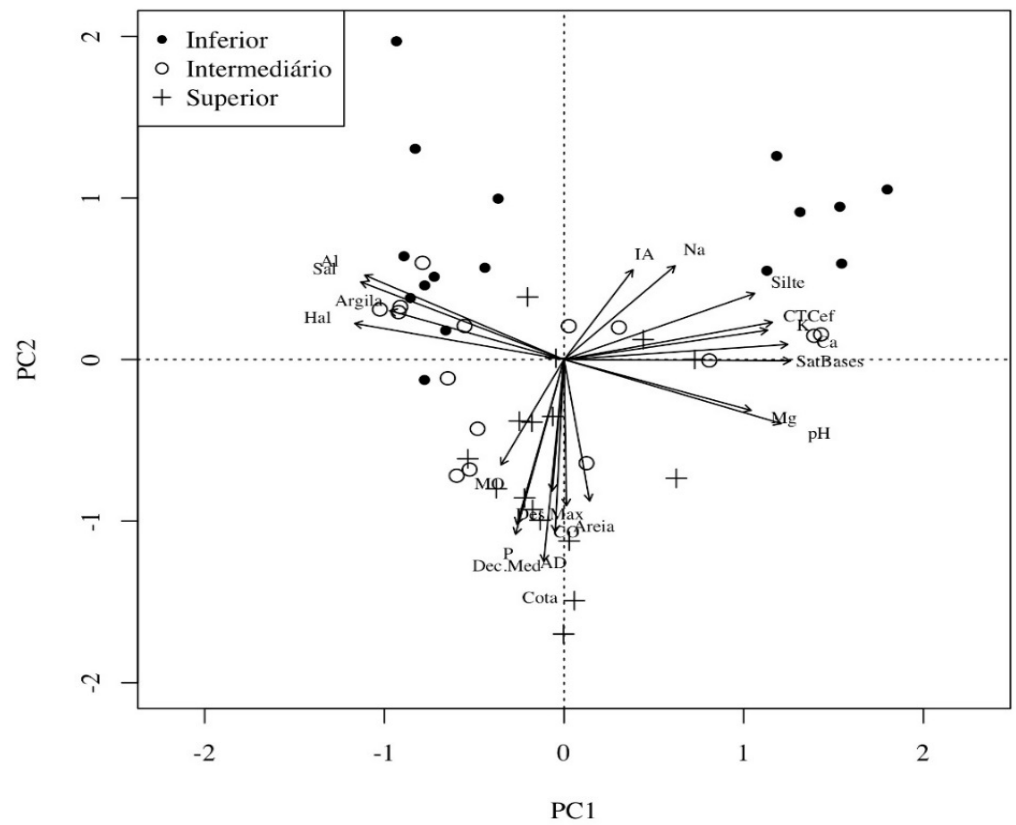

FIGURA 2: Ordenação produzida por Análise de Componentes Principais (PCA) para as variáveis ambientais de um remanescente florestal localizado em área de transição entre Floresta Ombrófila Mista e Floresta Estacional Decidual em São José do Cerrito-SC. IA = impacto ambiental; $\mathrm{Na}=$ teor de sódio; Silte $=$ teor de silte; $\mathrm{CTCef}=\mathrm{CTC}$ efetiva; $\mathrm{K}=$ teor de potássio; $\mathrm{Ca}=$ teor de cálcio; SatBases = saturação por bases; $\mathrm{Mg}$ = teor de magnésio; $\mathrm{pH}=\mathrm{pH}$ em água; Areia = teor de areia; Des.Max = desnível máximo; $\mathrm{CO}=$ carbono orgânico; $\mathrm{AD}=$ abertura do dossel; Cota = cota altitudinal; Dec.Med = declividade média; $\mathrm{P}$ = teor de fósforo; $\mathrm{MO}$ = teor de matéria orgânica; Hal = teor de hidrogênio mais alumínio; Argila = teor de argila; $\mathrm{Sal}=$ saturação por alumínio; $\mathrm{Al}=$ teor de alumínio.

FIGURE 2: Ordination produced by Principal Component Analysis (PCA) for the environmental variables of a forest remnant located in a transition area between Araucaria and Seasonal Dedicidual forests, in the municipality of São José do Cerrito, SC state. IA = environmental impact; $\mathrm{Na}=$ sodium content; Silte = silt content; $\mathrm{CTC}$ e $=$ effective cation exchange capacity; $\mathrm{K}=$ potassium content; $\mathrm{Ca}=\mathrm{Calcium}$ content; SatBases $=$ base saturation; $\mathrm{Mg}=$ magnesium content; $\mathrm{pH}=\mathrm{pH}$ in water; Areia $=$ sand content; Des. $\mathrm{Max}=$ maximum topographic slope $\mathrm{CO}=$ organic carbon; $\mathrm{AD}=$ canopy opening; Cota $=$ altitudinal quota; Dec.Med = average slope; $\mathrm{P}=$ phosphorus; $\mathrm{MO}$ = organic matter content; Hal aluminum + hydrogen content; Argila = clay content; $\mathrm{Sal}=$ aluminum saturation; $\mathrm{Al}=$ aluminum content . 
Os gradientes ambientais sintetizados pelos dois primeiros eixos da PCA não influenciaram de forma significativa as taxas de dinâmica $(p>0,05)$ (Tabela 4), indicando que há outros fatores, não analisados, que estão influenciando essas taxas. No entanto, conforme já analisado de forma indireta pela setorização da área, as taxas de dinâmica distintas entre os setores indicam que a lâmina de água, provavelmente, é a variável mais influente nas mudanças observadas dois anos após o enchimento do lago. Outros autores já encontraram elevada influência das inundações sobre a composição florístico-estrutural (e.g. FERREIRA, 2000; BIANCHINI et al., 2003; BARDDAL et al., 2004; SILVA et al., 2007; 2009; FERREIRA et al., 2013) e sobre a dinâmica em florestas (e.g. APPOLINARIO; OLIVEIRA FILHO; GUILHERME, 2005; SILVA et al., 2011; NUNES et al., 2016). Os solos de áreas inundáveis, quando saturados de água, não permitem o metabolismo aeróbico de plantas. Nessas situações, além do oxigênio ser um fator limitante, existe outros fatores seletivos que limitam o estabelecimento das plantas, como aqueles relacionados ao processo de sedimentação (SILVA et al., 2012).

TABELA4: Modelos de regressões logísticas para as taxas demográficas do componente arbóreo de um remanescente florestal localizado em área de transição entre Floresta Ombrófila Mista e Floresta Estacional Decidual em São José do Cerrito-SC.

TABLE 4: Logistic regressions models for the demographic rates of tree component in an forest remnant located in a transition area between Araucaria and Season Decidual forests, in the municipality of São José do Cerrito, SC state.

\begin{tabular}{ccccccccc}
\hline Eixos da PCA & $\mathrm{M}$ & $p$ & $\mathrm{R}$ & $p$ & $\mathrm{P}$ & $p$ & $\mathrm{G}$ & $p$ \\
\hline Eixo 1 PCA (fertilidade) & 0,16 & 0,5 & 0,01 & 0,96 & 0,07 & 0,97 & 0,15 & 0,91 \\
\hline & & & & & & & & \\
\hline $\begin{array}{c}\text { Eixo 2 PCA (topografia } \\
\text { e abertura do dossel) }\end{array}$ & 0,35 & 0,19 & $-0,24$ & 0,3 & 0,43 & 0,82 & $-0,19$ & 0,87 \\
& & & & & & & & \\
\hline
\end{tabular}

Em que: $\mathrm{M}=$ taxa de mortalidade; $\mathrm{R}=$ taxa de recrutamento; $\mathrm{G}=$ taxa de ganho em área basal; $\mathrm{P}=$ taxa de perda em área basal; $p=$ significância das variáveis conforme modelos logísticos.

\section{CONCLUSÕES}

Adinâmica na área estudada foi caracterizada pela estabilidade na riqueza e em número de indivíduos, porém, com maior ganho que perda em área basal, indicando processo de acúmulo de biomassa. No entanto, observa-se que, entre os setores da floresta, há distinções, sendo o setor 1 caracterizado pela maior taxa de perda em área basal, possivelmente devido à influência da proximidade com o reservatório. Apesar disso, de forma geral, não houve relação das taxas de dinâmica com as variáveis ambientais analisadas, indicando que, na área estudada, a influência encontrada dos setores sobre o crescimento das árvores está associada a variáveis não diretamente analisadas, como a influência do reservatório que, provavelmente, está ocasionando à estagnação do crescimento de algumas espécies e perdas em outras mais sensíveis. A observação da distinção entre os setores, especialmente em relação à perda em área basal, confirma esse padrão. Dessa forma, o presente estudo evidencia o impacto das inundações no desenvolvimento da floresta e indica que, dois anos após o enchimento do reservatório, foi possível perceber os efeitos do enchimento do lago da hidrelétrica na comunidade arbórea, o que pode levar, ao longo do tempo, à redução de algumas populações não adaptadas no setor inferior, e consequentes mudanças florísticas. 


\section{AGRADECIMENTOS}

À FUMDES, pela concessão da bolsa de mestrado à primeira autora do trabalho, e ao CNPq, pelas bolsas de produtividade em pesquisa concedidas ao segundo e terceiro autores. À FAPESC, pelo apoio financeiro por meio do programa PAP/UDESC.

\section{REFERÊNCIAS}

ALVAREZ, V. V. H. et al. Interpretação dos resultados das análises de solos. In: RIBEIRO, A. C.; GUIMARAES, P. T. G.; ALVAREZ, V. V. H. (Org.). Recomendação para o uso de corretivos e fertilizantes em Minas Gerais: $5^{\circ}$ Aproximação. Viçosa, MG: Comissão de Fertilidade do Solo do Estado de Minas Gerais, 1999. p. 25-32.

AGÊNCIA NACIONAL DE ENERGIA ELÉTRICA (Brasil). Anexo VIII ao edital de leilão $\mathbf{N}^{\circ}$. 03/2010-ANEEL. Processo ${ }^{\circ}$. 48500.000883/2010-23. [s. 1.]: ANEEL, 2010.

APPOLINARIO, V.; OLIVEIRA FILHO, A. T.; GUILHERME, F. A. G. Tree population and community dynamics in a Brazilian tropical semideciduous forest. Revista Brasileira de Botânica, São Paulo, v. 28 , n. 2, p. 347-360, 2005.

ARMSTRONG, W.; BRAENDLE, R.; JACKSON, M. B. Mechanisms of flood tolerance in plants. Acta Botanica Neerlandica, Hoboken, v. 43, n. 2, p. 307-358, 1994.

AYERS, R. S.; WESTCOT, D. W. Qualidade de água na agricultura. Campina Grande: UFPB, 1991. $218 \mathrm{p}$.

BARDDAL, M. L. et al. Caracterização florística e fitossociológica de um trecho sazonalmente inundável de floresta aluvial, em Araucária, PR. Ciência Florestal, Santa Maria, v. 14, n. 2, p. 37-50, 2004.

BIANCHINI, E. et al. Diversidade e estrutura de espécies arbóreas em área alagável do município de Londrina, Sul do Brasil. Acta Botânica Brasilica, Belo Horizonte, v. 17, n. 3, p. 405-419, 2003.

BJORNSTAD, O. N. NCF: spatial nonparametric covariance functions. R package version 1.1-5. [s. 1.: s. n.], 2013. Disponível em: $<\mathrm{http}: / / \mathrm{http}: / / C R A N . R-p r o j e c t . o r g / p a c k a g e=n c f>$. Acesso em: 16 jun. 2016.

BOTREL, R. et al. Influência do solo e topografia sobre as variações da composição florística e estrutura da comunidade arbóreo-arbustiva de uma floresta estacional semidecidual em Ingaí, MG. Revista Brasileira de Botânica, São Paulo, v. 25, n. 2, p. 195-213, 2002.

BUDKE, J. C. et al. Bamboo dieback and tree regeneration responses in a subtropical forest in South America. Forest Ecology and Management, Amsterdam, v. 260, n. 8, p. 1345-1349, 2010.

EMBRAPA. Conceitos de fertilidade do solo e manejo adequado para as regiões tropicais. Campinas: Embrapa Monitoramento por Satélite, 2010. 26 p. (Boletim de Pesquisa e Desenvolvimento, 8).

EMBRAPA. Sistema brasileiro de classificação de solos. 2. ed. Rio de Janeiro: EMBRAPA, 2006. 306 p. EMBRAPA. Solos do Estado de Santa Catarina. Rio de Janeiro: Embrapa Solos, 2004. 726 p.

EMPRESA DE PESQUISA AGROPECUÁRIA E EXTENSÃO RURAL DE SANTA CATARINA. Zoneamento agroecológico e socioeconômico do estado de Santa Catarina. Florianópolis: EPAGRI, 1999. CD-ROM.

FERREIRA, L. V. Effects of flooding duration on species richness, floristic composition and forest structure in river margin habitat in Amazonian blackwater forests: implications for future design of protected areas.

Biodiversity and Conservation, New York, v. 9, n. 1, p. 1-14, 2000.

FERREIRA, L. V. et al. Impacts of hydroelectric dams on alluvial riparian plant communities in eastern Brazilian Amazonian. Anais da Academia Brasileira de Ciências, Rio de Janeiro, v. 85, n. 3, p. 1013-1023, 2013.

FORMENTO, S.; SCHORN, L. A.; RAMOS, R. A. Dinâmica estrutural arbórea de uma Floresta Ombrófila Mista em Campo Belo do Sul. Cerne, Lavras, v. 10, n. 2, p. 196-212, 2004.

GIRAUDOUX, P. Pgirmess: Data Analysis in Ecology. R package version 1.6.2. [s. 1.: s. n.], 2015. Disponível em: $<$ http://CRAN.R-project.org/package=pgirmess $>$. Acesso em: 16 jun. 2016.

GUILHERME, F. A. G. et al. Effects of flooding regime and woody bamboos on tree community dynamics in a section of tropical semideciduous forest in South-Eastern Brasil. Plant Ecology, Nova York, v. 174, n. 1, p. 19-36, 2004. 
GUSSON, A. E. et al. Variações temporais na densidade de espécies lenhosas regenerativas em áreas impactadas por usinas hidrelétricas. Revista de Biologia e Ciências da Terra, São Cristóvão, v. 12 , n. 1 , p. $83-88,2012$.

HIGUCHI, P. et al. Influência de variáveis ambientais sobre o padrão estrutural e florístico do componente arbóreo, em um fragmento de Floresta Ombrófila Mista Montana em Lages, SC. Ciência Florestal, Santa Maria, v. 22, n. 1, p. 79-90, 2012.

IBGE. Manual técnico da vegetação brasileira. Rio de Janeiro: Fundação Instituto Brasileiro de Geografia e Estatística, 2012. $271 \mathrm{p}$.

IVANAUSKAS, N. M. Estudo da vegetação presente na área de contato entre formações florestais em Gaúcha do Norte - MT. 2002. 201 f. Tese (Doutorado em Biologia Vegetal) - Universidade Estadual de Campinas, Campinas, 2002.

KANIESKI, M. R. Estudo dendroecológico de Sebastiania commersoniana (Baill.) L.B.Sm. \& R.J.Downs e de arbóreas invasoras em uma Floresta Ombrófila Mista Aluvial, sul do Brasil. 2013. 127 f. Tese (Doutorado em Engenharia Florestal) - Universidade Federal do Paraná, Curitiba, 2013.

KOLB, R. M. et al. Anatomia ecológica de Sebastiania commersoniana (Baillon) Smith \& Downs (Euphorbiaceae) submetida ao alagamento. Revista Brasileira de Botânica, São Paulo, v. 21, n. 3, p. 305-312, 1998.

KORNING, J.; BALSLEV, H. Growth and mortality of trees in Amazonian tropical rain forest in Ecuador. Journal of Vegetation Science, Hoboken, v. 4, n. 1, p. 77-86, 1994.

LEMMON, P. A spherical densiometer for estimating forest overstory density. Forest Science, Bethesda, v. 2, n. 1, p. 314-320, 1956.

LIEBERMAN, D. et al. Mortality patterns and stand turnover rates in a wet tropical forest in Costa Rica. Journal of Ecology, Hoboken, v. 73, n. 3, p. 915-924, 1985.

LOPES, S. F. et al. Impacts of artificial reservoirs on floristic diversity and plant functional traits in dry forests after 15 years. Brazilian Journal of Biology, São Carlos, v. 75, n. 3, p. 548-557, 2015.

MARCON, A. K. et al. Variação florístico-estrutural em resposta à heterogeneidade ambiental em uma floresta nebular em Ububici, Planalto Catarinense. Scientia Forestalis, Piracicaba, v. 42, n. 103, p. 439-450, 2014.

NILSSON, C.; BERGGREN, K. Alterations of riparian ecosystems caused by river regulation. BioScience, Uberlândia, v. 50, n. 9, p. 783-792, 2000.

NUNES, M. H. et al. Dinâmica de populações de espécies arbóreas em fragmentos de floresta aluvial no sul de Minas Gerais, Brasil. Floresta, Curitiba, v. 46, n. 1, p. 57-66, 2016.

OKSANEN, J. et al. Vegan: Community Ecology Package. R package version 2.2-1. [s. 1.: s. n.], 2015. Disponível em: $<$ http://CRAN.R-project.org/package=vegan>. Acesso em: 16 jun. 2016.

OLIVEIRA, A. B.; GOMES FILHO, E.; ENÉAS FILHO, J. O problema da salinidade na agricultura e as adaptações das plantas ao estresse salino. Enciclopédia Biosfera, Goiânia, v. 6, n. 11, p. 1-16, 2010.

OLIVEIRA FILHO, A. T. et al. Differenciation of streamside and upland vegetation in an area of montane semideciduous forest in southeastern Brasil. Flora, Amsterdam, v. 189, p. 287-305, 1994a.

OLIVEIRA FILHO, A. T. et al. Dinâmica da comunidade e populações arbóreas da borda e interior de um remanescente florestal na Serra da Mantiqueira, Minas Gerais, em um intervalo de cinco anos (1999-2004).

Revista Brasileira Botânica, São Paulo, v. 30, n. 1, p. 149-161, 2007.

OLIVEIRA FILHO, A. T. et al. Effect of flooding regime and understorey bamboos on the physiognomy and tree species composition of a tropical semideciduous forest in Southeastern Brasil. Vegetatio, Nova York, v. 113, n. 2, p. 99-124, 1994b.

OLIVEIRA FILHO, A. T.; MELLO, J. M.; SCOLFORO, J. R. Effects of past disturbance and edges on tree community structure and dynamics within a fragment of tropical semideciduous forest in south-eastern Brazil over a five years period (1987-1992). Plant Ecology, Nova York, v. 131, n. 1, p. 45-66, 1997.

R CORE TEAM. R: a language and environment for statistical computing. Vienna: R Foundation for Statistical Computing, 2015. Disponível em: <http://www.R-project.org/>. Acesso em: 16 jun. 2016.

SALAMI, B. et al. Influência de variáveis ambientais na dinâmica do componente arbóreo em um fragmento de Floresta Ombrófila Mista em Lages. Scientia Forestalis, Piracicaba, v. 42, n. 102, p. 197-207, 2014. SANTOS, K. F. et al. Regeneração natural do componente arbóreo após a mortalidade de um maciço de 
taquara em um fragmento de Floresta Ombrófila Mista em Lages - SC. Ciência Florestal, Santa Maria, v. 25 , n. 1, p. 107-117, 2015.

SHEIL, D.; MAY, R. M. Mortality and recruitment rate evaluations in heterogeneous tropical forests. Journal of Ecology, Hoboken, v. 84, n. 1, p. 91-100, 1996.

SILVA, A. C. et al. Comparação florística de florestas inundáveis das regiões Sudeste e Sul do Brasil. Revista Brasileira de Botânica, São Paulo, v. 30, n. 2, p. 257-269, 2007.

SILVA, A. C. et al. Dinâmica de uma comunidade arbórea após enchente em fragmentos florestais no sul de Minas Gerais. Revista Árvore, Viçosa, MG, v. 35, n. 4, p. 883-893, 2011.

SILVA, A. C. et al. Florestas inundáveis: ecologia, florística e adaptações das espécies. Lavras: Ed. UFLA, 2012. $167 \mathrm{p}$.

SILVA, A. C. et al. Florística e estrutura da comunidade arbórea em fragmentos de floresta aluvial em São Sebastião da Bela Vista, Minas Gerais. Revista Brasileira de Botânica, São Paulo, v. 32, n. 2, p. 283-297, 2009.

SILVA, A. C.; HIGUCHI, P.; VAN DEN BERG, E. Effects of soil water table regime on tree community species richness and structure of alluvial forest fragments in Southeast Brazil. Brazilian Journal of Biology, São Carlos, v. 70, n. 3, p. 465-471, 2010.

SOUZA, C. G. Manual técnico de pedologia. Rio de Janeiro: Fundação Instituto Brasileiro de Geografia e Estatística, 2007. 104 p. (Série: Manuais Técnicos em Geociências, v. 4).

SPATHELF, P. et al. Análise dendroecológica de Ocotea pulchella Nees et Mart. ex Nees (canela-lageana) na Serra Geral de Santa Maria, RS, Brasil. Ciência Florestal, Santa Maria, v. 10, n. 1, p. 95-108, 2000.

VALE, V. S. et al. Fast changes in seasonal forest communities due to soil moisture increase after damming. Revista de Biología Tropical, São José, v. 61, n. 4, p. 1091-1917, 2013.

WERNECK, M. S.; FRANCESCHINELLI, E. V. Dynamics of a dry forest fragment after exclusion of human disturbance in southeastern Brazil. Plant Ecology, Nova York, v. 174, n. 2, p. 337-346, 2004.

WIEDENROTH, E. M. Responses of roots to hypoxia: their structural and energy relations with the whole plant. Environmental and Experimental Botany, Amsterdam, v. 33, n. 1, p. 41-51, 1993.

ZUUR, A. et al. Mixed effects models and extensions in ecology with R. Amsterdam: Springer Science \& Business Media, 2009. 574 p. 